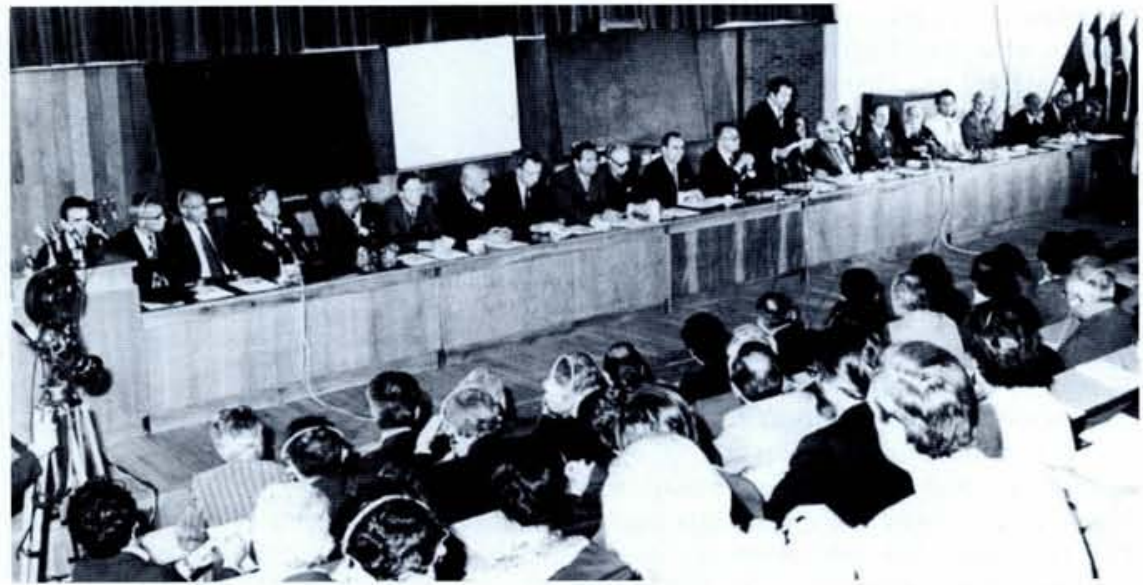

The opening of the third General Conference in Bucharest in September 1975.
My passport was confiscated in the autumn of 1969 and from October I was prevented from participating in EPS activities outside Czechoslovakia (I was to lose my position at the Nuclear Research Institute in 1970 and I remained unemployed until 1974). The secretariat was thus gradually paralyzed and Council was informed in 1973 that the Academy had decided to close it down.

\section{Continuing Difficulties}

In the spring of 1973, the Czechoslovak Academy, wishing to improve its reputation abroad following several dismissals similar to mine, invited the EPS to hold the 3rd General Conference in Prague in 1975. The EPS President, H.B.G. Casimir, welcomed the invitation in his reply to the Academy's President, but indicated that Janouch had no possibility to earn a living as a physicist. He wrote: "I wonder whether you have any advice or information to give on this matter." The response was cold: "Owing to the difficulties you have met while discussing our original proposal... I sincerely regret to inform you that we came to a conclusion to cancel our proposal..." Casimir's subsequent attempts to discuss the matter in Prague were unsuccessful. East European members supported Casimir's approach, and I. Ursu from Romania came up with an invitation to hold the conference in Bucharest, where infractions of human rights at least did not generally involve physicists.
In the autumn, a Czechoslovakian delegation proposed at a meeting of east European representatives that physicists should either leave EPS or at least cool down relations because of the support for Janouch. Rejection of both proposals and the transfer of the General Conference to Bucharest probably induced the Czechoslovak Academy and/or the authorities to allow me to leave the country, which I did it at the end of 1973 with my family (with a passport valid for 5 years, only to be deprived of citizenship in 1975).

I was elected to the EPS Council as a delegate of the Individual Ordinary Members in 1983, the year before the 6 th General Conference was scheduled to take place in Prague following an invitation from the Czechoslovak Academy. Although assurances were given about entrance visas, my application was rejected. Following protests, the President of the Academy stated in a widely circulated letter "that the activities of Professor Janouch have threatened to split the EPS". The Executive Committee made repeated efforts to persuade the authorities to change their minds, as did the conference organizers. But they remained obdurate and it was with much hesitation that the decision was taken to go ahead with the meeting, the overriding argument being that whilst the principle of free access by "classes" of physicists was inviolate, the EPS could not provide against States designating individuals as persona non grata. Some felt the Executive's attitude to be complaisant: I campaigned against it as did John Ziman who was scheduled to present the Powell Memorial Lecture and who refused to attend, letting this be widely known. Nevertheless, EPS gave considerable publicity to the visa refusal, the President issued a statement at the General Meeting, and the Executive appointed a committee under John Charap to look into the matter. It concluded that the reaction could have been more vigorous and called for vigilance in the future. But it had no simple formula to offer.

Europe has since changed considerably. The problems I write about seem now to belong to the past. I hope that EPS can concentrate on physics and its position in society, for the issues may turn out to be as difficult to tackle as those dealt with during the first 20 years.

\title{
Anticipating EPS on a Reduced Scale
}

\section{G.-J. Béné, Geneva}

I was informed at the end of the summer of 1966 of the consultations undertaken by Bernardini in what G. Saragat, the President of the Republic of Italy, put it in his telegram to the Pisa meeting in April 1966 as "the possibility of forming a single and free association of European physicists". The proceedings of this meeting, distributed the following September, had the merit of clearly posing the problem which was soon to be at the centre of the often lively discussions of the Steering Committee; should we found a new association with (physical or legal) individual members, or should we opt for a looser federation of national associations? The question was not simple and I felt then that the experience of the Groupement Ampère might well be of some use in this discussion.

\section{The Groupement Ampère}

Creating the Group was especially laborious for it was necessary to find a host laboratory, a source of finance, etc. But the problems were clear: in the aftermath of World War II, laboratories, notably those removed from the main cities, lacked equipment, literature and many other resources. R. Freymann from Paris had the idea at a conference in Oxford in 1948 to create a liaison bulletin to exchange information and to ask for support from the Centre National de la Recherche Scientifique (CNRS) in France to purchase surplus American equipment for joint use.

The perspective was a national group that Freymann immediately baptised AMPERE (atomes et molécules par études radio-électriques). Decisive steps were taken thanks to 
help from the Physics Laboratory of the Ecole Normale Supérieure in Paris that was heavily engaged in spectroscopy at radio-frequencies and whose Director, Yves Rocard, and Professors, Alfred Kastler and Pierre Grivet, were in a position to convince the CNRS authorities of the importance of the initiative.

While the first Ampère conference, in Paris in 1952, was restricted to CNRS staff, its perspectives were necessarily international. Thus, although working at the University of Geneva, I was able to attend, albeit primarily because I was supported by the CNRS. Belgian specialists soon found out about the work presented in Paris and immediately announced that they wished to participate in the Group; the first issue of the Bulletin Ampere in 1953 made it clear that French-speakers from neighbouring countries were welcome. The frontiers were pushed back progressively at subsequent meetings and by 1955 , most laboratories in western Europe participated at the annual conferences which, however, continued to be held in France.

Profound changes came about in 1956 when the annual conference was held outside France (in Geneva) and a scientist from eastern Europe was invited (A. Lösche from Leipzig). In order to facilitate future relations with this part of Europe, Geneva, an international city, was also chosen for the Group's Secretariat. Subsequent conferences were held in France, Great Britain and Italy. The building of the Berlin Wall only a month before the 1961 conference was due to to be held in Leipzig clearly jeopardized this first step eastwards. But the meeting went ahead and while attendance was somewhat reduced, most radio-frequency specialists active in eastern Europe were present. They were to continue to participate: the game had been won! By 1965 , shortly before the annual meeting in Ljubliana, the Group numbered some $\mathbf{5 5 0}$ physicists from 12 west European and 8 east European countries.

\section{Essential Ingredients}

The Groupement Ampère found this European dimension progressively, from pressure from physicists themselves. Functioning was occasionally difficult but it nonetheless improved continuously, and this augured well for a European society of physics that would make possible fruitful contacts on a larger scale. Unity across Europe would help attain the goal of bringing together physicists from very different backgrounds, and with varied resources, into an international organization on a sufficiently reduced geographical scope to ensure regular, quasipermanent, cooperation.

We had learnt in the Group that enabling the free circulation of people and payments called for much imagination. Necessary ingredients were: a modest secretariat based in a neutral country with an international tradition; the minimum of legal constraints (the Group's statutes were in fact only drawn up in 1969 with the view to joining EPS); individual membership fees payable as subscriptions by libraries to the Bulletin Ampere; the possibility to suspend payments or to arrange long-term credits; meetings organized in Europe, to minimize travel costs, by the laboratories concerned on condition that no physicist could be excluded on the basis of nationality.

Above all, we collaborated with national associations in organizing our meetings.

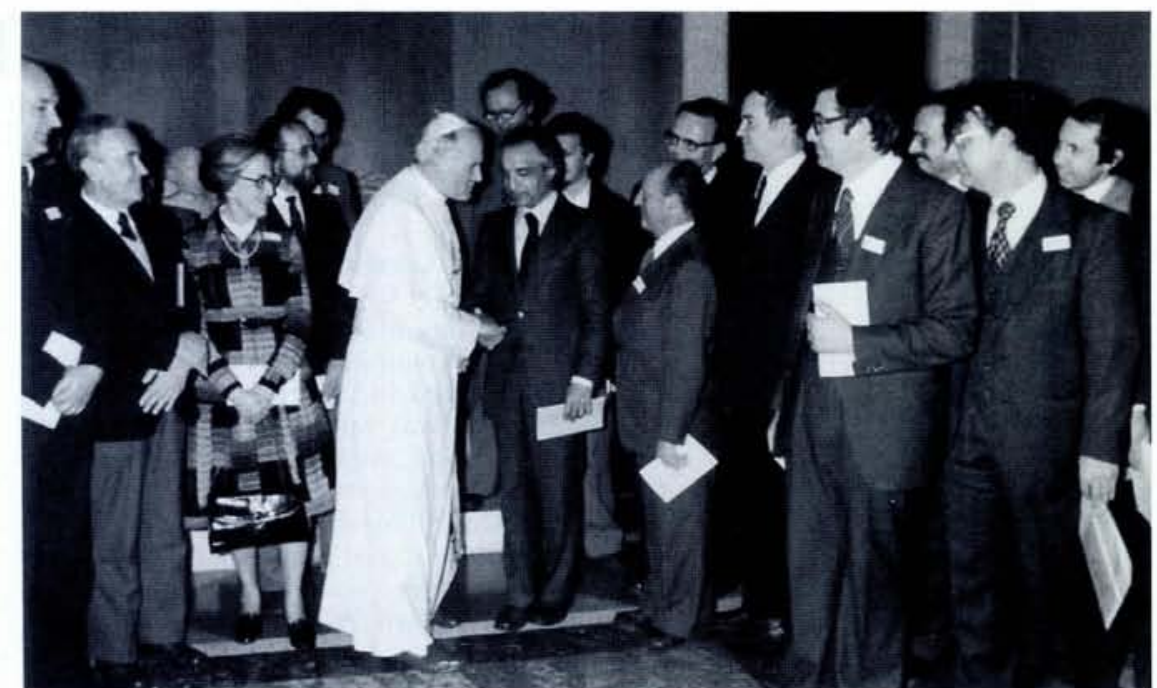

But in certain countries - particularly those in eastern Europe - the heads of the associations were not really independent of the political authorities, and this threatened the effectiveness of collaboration. Fortunately, even larger numbers of physicists were aware of the increasing need for frequent personal contacts with colleagues from neighbouring countries.

$\mathrm{I}$ argued at the Steering Committee meetings that organizing the future Society as a federation would run the risk of clashes between national interests, and place EPS at the mercy of unacceptable demands from the more powerful members. We had an example of this at the Geneva meeting of the Steering Committee in November 1966 when one delegation demanded that all of the discussions during the meeting figure in the records, which would have brought the secretariat to a standstill and caused useless expenditure. The solution proposed after the London meeting in May 1967 was a compromise: not only was EPS to be really independent, a sine qua non if it were to work, but the authority of national societies was reinforced within their respective countries.
His Holiness Jean Paul II flanked by members of the EPS Council during an audience given in the Vatican in 30 March 1979. From the left, E.R. Dobbs (Chairman, Publications Committee), A. Strzalkowski (Chairman. Nuclear Physics Division), E.A. Müller, (EPS Vice-Treasurer), C. Le Pair, V. Ruuskanen, His Holiness, V. Goldenski, A. Zichichi (EPS President), J. Béné, G.-J. Béné, A. Lösche, S. Kapitza, G. Picozza, G. Preparata, M. Guenin, and R. Scrimaglio (Secretary, Physics and Society Committee). The audience took place during the Seminar on European Great Projects, the first of the EPS "large-facilities" meetings.

\section{Simplify Measurements of Magnetic Properties with Instruments from Gryophysics}

With the new state-of-the-art Gaussmeters from Lake Shore Cryotronics and their industry-standard ac susceptometer/dc magnetometers and VSM magnetometers complementing our range of industrial hysteresigraphs and coercimeters from LDJ, Cryophysics can now help with virtually every magnetic measurement. Contact René Koch in Geneva for details. 